\title{
Effect of the Elaboration Conditions on the Structural, Morphological and Luminescence Properties of ZnO Nanopowders
}

\author{
L. $\operatorname{ArAB}^{a, *}$, K. Guergouri ${ }^{b}$ \\ ${ }^{a}$ Laboratoire des matériaux semiconducteurs et métalliques, Département des sciences de la matière, \\ Université Mohamed Kheider, Biskra 07000, Algérie \\ ${ }^{b}$ Département de Physique, Faculté des Sciences Exactes, \\ Université Larbi Ben M'Hidi 04000 Oum El Bouaghi, Algérie
}

\begin{abstract}
Pure $\mathrm{ZnO}$ nanopowders were synthesized by the sol-gel method, which has several advantages, among which we include, achieving low temperature deposition and synthesis of new hybrid organo-mineral materials. The effect of the elaboration conditions (the elaboration concentrations ratio of precursors $\left(\mathrm{C}_{Z} / \mathrm{C}_{A}\right)$, the gelling temperature $\left(T_{g}\right)$ and the gelling time $\left.\left(t_{g}\right)\right)$ on the structural, morphological and luminescence properties of $\mathrm{ZnO}$ nanopowders has been investigated. The chemical composition of the powders, determined by FTIR spectroscopy, indicate the exclusive presence of $\mathrm{Zn}-\mathrm{O}$ bonds, as it is shown by the XRD spectra. The XRD results indicate also that the synthesized $\mathrm{ZnO}$ powder is a solid solution, crystallizing in pure würtzite structure with a minimum grain size of about $23 \mathrm{~nm}$ for the powders prepared using: $\mathrm{C}_{Z} / \mathrm{C}_{A}=0.06 \%, T_{g}=130{ }^{\circ} \mathrm{C}$ and $T_{g}=4 \mathrm{~h}$. The morphological aspect, given by the SEM images, revealed that the powders are made of sheets, consisting of small particles agglomerated together. The photoluminescence study of the $\mathrm{ZnO}$ powders shows spectra with luminescence peaks from green to ultraviolet light, the more intensive emission is connected to the peaks of the blue luminescence.
\end{abstract}

DOI: 10.12693 /APhysPolA.127.940

PACS: 81.05.Dz, 81.07.Wx, 81.20.Fw, 07.57.Ty, 78.55.Qr, 68.37.Hk

\section{Introduction}

$\mathrm{ZnO}$ remains a very interesting material because of its properties, allowing it to cover a wide field of applications. Among these numerous properties we cite, in particular, that it is a semiconductor with a wide band gap $(3.37 \mathrm{eV}$ at $300 \mathrm{~K})$ and it is transparent in the visible and near infrared. The applications of $\mathrm{ZnO}$ in many fields such as: the manufacture of varistors, cathodoluminescence [1-4], photoluminescence [5], electroluminescence, photocatalysis [6] and many other areas such as: piezoelectricity [7], its use as a substrate for the epitaxy of GaN thin layers [8] and the decontamination of water, still attract the interest of researchers and industry. The powder technology occupies a very important place in the industry, continuously creating many scientific curiosities. Powder production process is classified according to the techniques used [6, 9-12], the diversity of applications and the control of certain characteristics such as the morphology and the grain size. Among the methods used to elaborate $\mathrm{ZnO}$ nanopowders, we have chosen in this study the sol-gel root, which is a simple and nonexpensive method. This study is part of the development of new material properties, intended for new applications such as: biomaterials, inorganic membranes [13], sensors and photonic materials [14-17]. In this work, we have

*corresponding author; e-mail: louiza.arab@gmail.com tried to elucidate the influence of the elaboration conditions (the precursor concentration, the temperature and the gelling time) on the properties of $\mathrm{ZnO}$ nanopowders.

\section{Experimental}

$\mathrm{ZnO}$ nanopowders were synthesized by the sol-gel technique. Zinc acetate dehydrate $\left(\mathrm{Zn}\left(\mathrm{CH}_{3} \mathrm{COO}\right)_{2}\right.$. $2 \mathrm{H}_{2} \mathrm{O}$ ) (purity $>99 \%$, Biochem-Chempharma) is used as starting material, ethylene glycol $\left(\mathrm{C}_{2} \mathrm{H}_{6} \mathrm{O}_{2}\right)$ (BiochemChempharma), and citric acid $\left(\mathrm{C}_{6} \mathrm{H}_{8} \mathrm{O}_{7}\right)$ (purity $>99 \%$ Prolab) are used as solvent and stabilizer, respectively. First the zinc acetate and citric acid were dissolved in ethylene glycol at a temperature $T_{g}$, called the gelling temperature. The concentration of zinc acetate and citric acid are $C_{Z}$ and $C_{A}$ respectively. Then the solutions were mixed, stirred and maintained at this temperature for a duration $t_{g}$, time of gelling, to yield a clear homogenous gel. Finally, to obtain $\mathrm{ZnO}$ powders, the gel was calcined at $500{ }^{\circ} \mathrm{C}$ in a furnace in air. In order to investigate the effect of elaboration conditions on the structural morphological and luminescence properties of $\mathrm{ZnO}$ nanopowders, we have changed the molar ratio of zinc acetate to citric acid $\left(C_{Z} / C_{A}\right)$, the temperature $\left(T_{g}\right)$ and the time of gelling $\left(t_{g}\right)$. Thus obtained $\mathrm{ZnO}$ nanopowders are characterized by X-ray diffractometer BRRUKERAXS D8 with CuK X-ray radiation $(\lambda=0.154056 \mathrm{~nm})$, FTIR spectroscopy (Thermonicolet), scanning electronic microscope (SEM) using the TESCAN VEGA TS $5130 \mathrm{MM}$, and photoluminescence using the Perkin Elmer LS 55. 


\section{Results and discussion}

Figure 1 exhibits X-ray diffraction patterns of $\mathrm{ZnO}$ nanopowders with different molar ratio $\left(C_{Z} / C_{A}\right)$. The positions of the diffraction peaks show that all the powders are polycrystalline $\mathrm{ZnO}$ having hexagonal würtzite structure. The full width at half maximum (FWHM) of the peaks increases with the decreasing molar ratio $\left(C_{Z} / C_{A}\right)$. This means that the grain size decreases with decreasing molar ratio $\left(C_{Z} / C_{A}\right)$, (Fig. 2). The grain size being evaluated by the Scherrer's formula [18]

$$
\Phi=\frac{0.9 \lambda}{\delta\left(2 \theta_{h k l}\right) \cos \theta_{h k l}},
$$

where $\lambda, \theta$ and $\delta$ are the X-ray wavelength (1.54056 $\AA$ ), the Bragg diffraction angle and the full width at halfmaximum (FWHM) respectively. The curve reaches the minimum of the grain size $(23 \mathrm{~nm})$ for the molar ratio equal to $0.06 \%$.
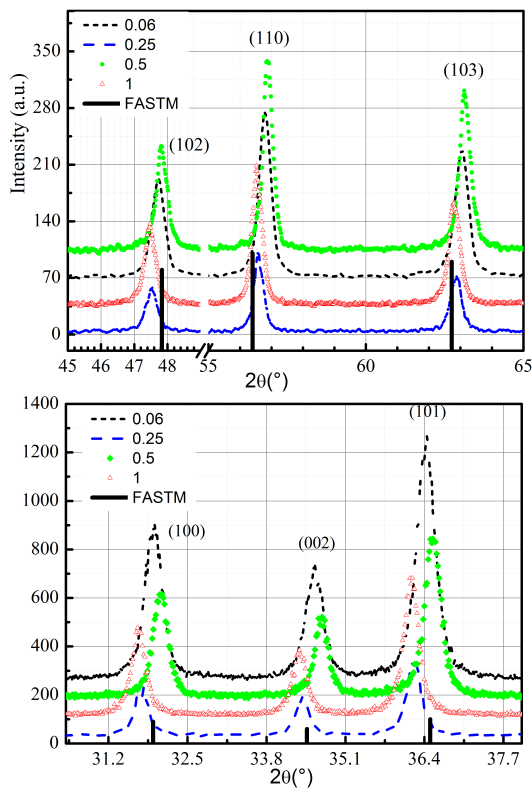

Fig. 1. X-ray diffraction patterns of $\mathrm{ZnO}$ nanopowders. Effect of molar ratio $C_{Z} / C_{A}(\%)$.

The lattice parameters of powders were calculated using equation

$$
d=\frac{a}{\sqrt{\frac{4}{3}\left(h^{2}+k^{2}+h k\right)+l^{2} \frac{a^{2}}{c^{2}}}},
$$

where $d$ is the interplanar distance, $a$ and $c$ are the lattice parameters and $(h, k, l)$ are the Miller indices. First of all we notice that the lattice parameters remain almost constant for all molar ratios.

FTIR results shown in Fig. 3 indicate that, for every mole ratio, absorption occur at the same wavenumber. We have recorded vibration at $430.80 \mathrm{~cm}^{-1}$, which is attributed to the $\mathrm{ZnO}$ band. The vibrations recorded at $1592.29,2366.95$ and $3441.47 \mathrm{~cm}^{-1}$ are attributed to the $\mathrm{C}=\mathrm{O}, \mathrm{CO}_{2}, \mathrm{O}-\mathrm{H}$ respectively. We think that these vibrations are due to the elaboration conditions (water, $\mathrm{CO}_{2}$, and so on).

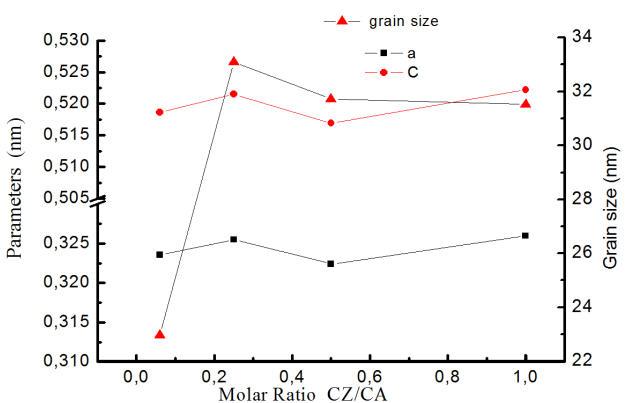

Fig. 2. Variation of lattice parameters and grain size as a function of molar ratio $C_{Z} / C_{A}(\%)$.

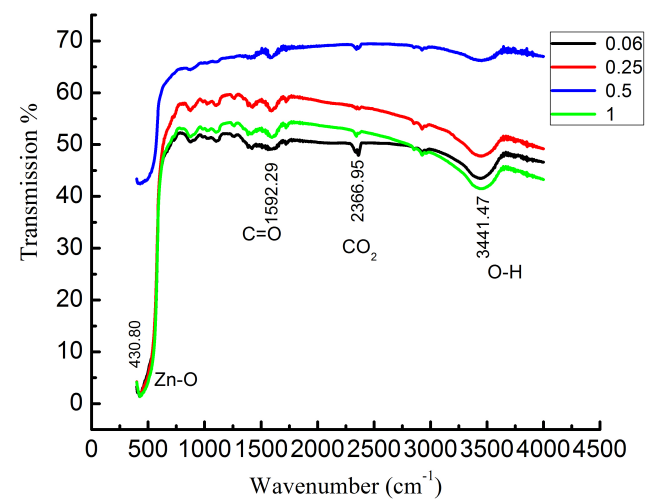

Fig. 3. FTIR spectra of $\mathrm{ZnO}$ nanopowders for different molar ratios $C_{Z} / C_{A}(\%)$.

SEM image (Fig. 4) of $\mathrm{ZnO}$ nanopowders prepared with molar ratio of $0.06 \%$, shows the morphology of the powders. We have observe shapes like sheets (Fig. 4a) with average thickness of about $5 \mathrm{~nm}$ (Fig. 4b). According to XRD data, grains reach the size of $23 \mathrm{~nm}$. Thus we can say that the sheets are actually made of small particles, agglomerated together.

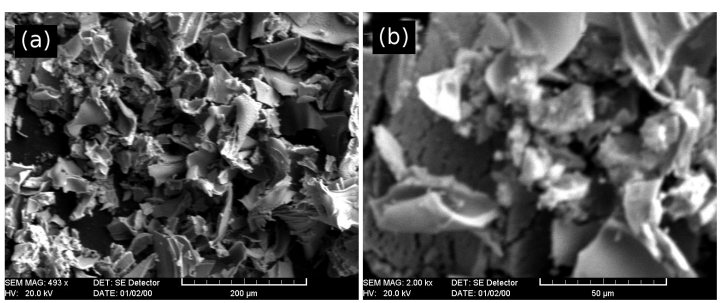

Fig. 4. SEM images of $\mathrm{ZnO}$ nanopowders prepared with molar ratio of $0.06 \%$.

Figure 5 shows EDS scans for $\mathrm{ZnO}$ nanopowder. Two peaks have been clearly observed, which are linked to zinc and oxygen. This indicates once again that the samples are free of contamination and reinforces the XRD results. We deduce also that the obtained powders of both sets have a proper stoichiometry.

PL spectrum at room temperature of pure $\mathrm{ZnO}$ nanopowder, synthesized with the molar ratio of $0.06 \%$ is shown in Fig. 6. The most important establishment is that the studied powder shows luminescence peaks in the spectrum range from green to the ultraviolet light, which 


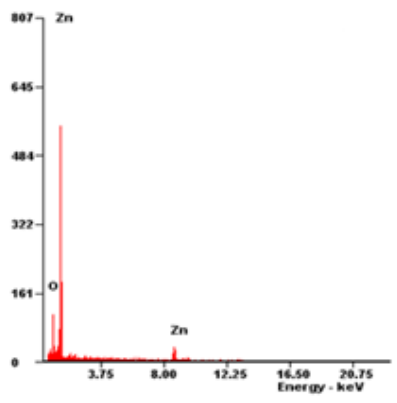

Fig. 5. EDS spectrum of $\mathrm{ZnO}$ nanopowders for molar ratio of $0.06 \%$.

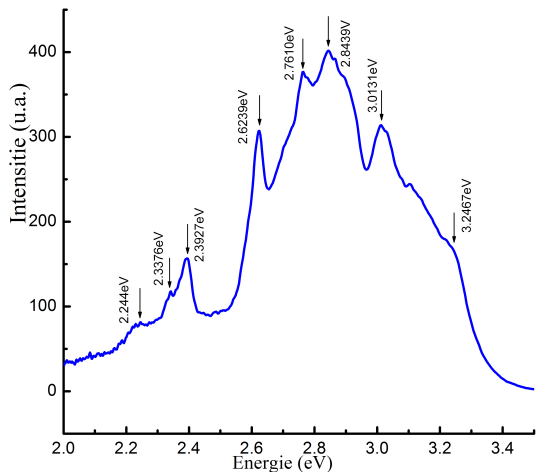

Fig. 6. Room temperature photoluminescence spectra of $\mathrm{ZnO}$ nanopowders for molar ratio of $0.06 \%$.

can be used to manufacture transmitters using, respectively, the green, the blue and the ultraviolet emissions. The studies of the defect connected to the luminescence peaks are presented in more detail in our previous paper [19].

\section{Conclusion}

Pure $\mathrm{ZnO}$ nanopowders have been elaborated by the sol-gel technique, with different molar ratio $C_{Z} / C_{A}(\%)$. The obtained substances have been characterized by means of XRD, FTIR, EDS, SEM, and PL to determine the effect of molar ratio on the structural, morphological and optical properties.

All the obtained powders follow the würtzite structure. They are constituted by very small grains. The smallest grain size has been recorded for the molar ratio of $0.06 \%$ and is equal to $23 \mathrm{~nm}$. The morphology of the powder, as shown by SEM images, is dominated by sheets with different sizes. The luminescence peaks cover the spectrum from green to the ultraviolet light. The most intensive are the peaks emitted in the blue luminescence region.

\section{References}

[1] N. Boulares, K. Guergouri, R. Zouaghi, N. Tabet, A. Lusson, F. Sibieude, C. Monty, physica status solidi (a) 201, 2319 (2004).

[2] D.P.Yu, G.Z.Bai, Y. Ding, Q.L. Hang, H.Z.Wang, Y.H. Zou, W.Qian, G.C. Xiong, H.T.Zhou, S.Q. Feng, Appl. Phys. Lett. 72, 3458 (1998).

[3] W.S. Shi, Y.F. Zheng, N. Wang, C.S. Lee, S.T. Lee, Appl. Phys Lett. 78, 3304 (2001).

[4] C.J. Lee, T.J. Lee, S.C. Lyu, Y. Zhang, H. Ruh, Appl. Phys. Lett. 81, 3648 (2002).

[5] T. Monteiro, C. Boemare, M.J. Soares, E. Rita, E. Alves, J. Appl. Phys. 93, 8995 (2003).

[6] S.Y. Kuo, W.C. Chena, F.I. Lai, C.P. Cheng, H.C. Kuo, S.C. Wang, W.F. Hsieh, J. Cryst. Growth 287, 78 (2006).

[7] V.E. Wood, A.E. Austin, Magnetoelectric Interaction Phenomena in Crystals, Gordon and Breach, London 1975.

[8] D.C. Look, D.C. Reynolds, J.R. Sizelove, R.L. Jones, C.W. Litton, G. Cantwell, W.C. Harsch, Solid State Commun. 105, 399 (1998).

[9] M. Shim, C. Wang, D.J. Norris, P. Guyot-Sionnest, MRS Bulletin 26, 1005 (2001).

[10] W.F. Miao, J. Ding, P.G Mcormick, R. Street, J. Appl. Phys. 79, 2079 (1996).

[11] M.R. Vaezi, S.K. Sadrnezhaad, Mater. Design 28, 515 (2007).

[12] J. Ma, F. Ji, H.-L. Ma, S.-Y. Li, Sol. Energ. Mat. Sol. C. 60, 341 (2000).

[13] L. Cot, A. Ayral, J. Durand, C. Guizard, N. Hovnanian, A. Julbe, A. Larbot, Solid State Sciences 2(3), $313(2000)$

[14] M. Shane, M.L. Mecartney, J. Mat. Scie. 25, 1537 (1990).

[16] S. Randall Holmes-Farley and Lynn C. Yanyo, $M R S$ Proceedings 180, 439 (1990).

[17] D.J. Taylor, B.D. Fabes, M.G. Steinthal, J. Mat. Res. Soc. Proc. 180, 1047 (1990).

[18] P. Scherrer, Bestimmung der Grösse und der Inneren Struktur von Kolloidteilchen Mittels Röntgenstrahlen, hrichten von der Gesellschaft der Wissenschaften, Göttingen, Mathematisch-Physikalische Klasse, Vol. 2, 1918

[19] L. Arab, S. Hamdelou, S. Harouni, K. Guergouri, L. Guerbous, J. Mat. Scie. and Eng.: B 177, 902 (2012). 